\title{
NEMATOIDES ASSOCIADOS A CINCO FRUTEIRAS EM RONDÔNIA, RO
}

\author{
Rodrigo Souza Santos ${ }^{1}$ \\ ${ }^{1}$ Embrapa Acre (Centro de Pesquisa Agroflorestal do Acre), Rio Branco, AC, Brasil. E-mail: rodrigo.s.santos@embrapa.br
}

\section{RESUMO}

Coletas de solo e raízes foram realizadas em plantas de abacaxi (Ananas comosus), açaíde-touceira (Euterpe oleracea), acerola (Malpighia sp.), pupunha (Bactris gasipaes) e cupuaçu (Theobroma grandiflorum), em Nova Califórnia, RO, em janeiro de 2011. As amostras foram processadas no Laboratório de Nematologia da Faculdade de Ciências Agrárias e Veterinárias (FCAV/UNESP) em Jaboticabal, SP. Em abacaxi, foram identificados Pratylenchus brachyurus (solo e raízes), Helicotylencus dihystera (solo e raízes) e Mesocriconema sp. (solo e raízes). Em açaí-de-touceira: Paratylenchus sp. (solo e raízes), Tylenchus sp. (solo e raízes) e Aphelencoides sp. (raízes). Em acerola: P. brachyurus (solo e raízes), Rotylenchulus reniformis (raízes), $H$. dihystera (solo), Mesocriconema sp. (solo e raízes) e Tylenchus sp. (raízes). Em pupunha: $H$. dihystera (solo e raízes), Paratylenchus sp. (solo) e Tylenchus sp. (solo). Em cupuaçu: Pratylenchus zeae (solo e raízes), Mesocriconema sp. (solo e raízes) e Tylenchus sp. (solo).

Palavras-chave: Fitossanidade, Fruticultura, Nematofauna, Patógenos

\section{NEMATODES ASSOCIATED TO FIVE FRUIT PLANTS IN THE STATE OF RONDÔNIA, BRAZIL}

\section{ABSTRACT}

Soil and root samples were collected from crops of pineapple (Ananas comosus), açai palm (Euterpe oleracea), acerola (Malpighia sp.), peach palm (Bactris gasipaes) and cupuaçu (Theobroma grandiflorum) in Nova Califórnia, state of Rondônia, Brazil, on January 2011. The samples were processed in the Nematology Laboratory of Faculty of Agricultural and Veterinary Sciences (FCAV/UNESP) in Jaboticabal, state of São Paulo, Brazil. In pineapple, one identified Pratylenchus brachyurus (soil and roots), Helicotylencus dihystera (soil and roots) and Mesocriconema sp. (soil and roots). In açai palm: Pratylenchus sp. (soil and roots), Tylenchus sp. (soil and roots) and Aphelencoides sp. (roots). In acerola: P. brachyurus (soil and roots), Rotylenchulus reniformis (roots), H. dihystera (soil), Mesocriconema sp. (soil and roots) and Tylenchus sp. (roots). In peach palm: H. dihystera (soil and roots), Paratylenchus sp. (soil) and 
Tylenchus sp. (soil). In cupuaçu: Pratylenchus zeae (soil and roots), Mesocriconema sp. (soil and roots) and Tylenchus sp. (soil).

Keywords: Phytosanitary, Fruit growing, Nematode community, Pathogens

\section{INTRODUÇÃO}

A fruticultura é uma atividade de grande importância econômica e social, particularmente para o segmento da agricultura familiar na região Norte do Brasil (NASCENTE \& ROSA NETO, 2005).

Em Rondônia, embora ainda incipiente, a fruticultura vem apresentando crescimento ao longo dos anos, destacandose como as principais frutas produzidas: cacau (Theobroma cacao L.), coco (Cocos nucifera L.), banana (Musa spp.), laranja (Citrus spp.), melancia [Citrullus lanatus (Thunb.)], abacaxi (Ananas comosus (L.) Merril.) e cupuaçu (Theobroma grandiflorum Schum.) (ROSA NETO \& ALMEIDA, 2007). Além destas fruteiras, o cultivo da acerola (Malpighia sp.), da pupunha (Bactris gasipaes Kunth.) e o extrativismo do açaí-de-touceira (Euterpe oleracea Martius) também são segmentos importantes da economia e nos últimos anos houve um incremento na produção e cultivo no Estado (FUNDAÇÃO BANCO DO BRASIL， 2010; MARQUES, 2012; MOURA, 2014). Dentre os problemas fitossanitários relacionados às frutíferas, os nematoides podem ser citados como um dos principais (CAMPOS et al., 2002), embora a importância destes patógenos seja subestimada ou conferida a algum outro fator, como deficiência nutricional, tratos culturais inadequados ou déficit hídrico (TIMMER et al., 2003).

$\mathrm{O}$ ataque de fitonematoides acarreta em grandes prejuízos no desenvolvimento e estabelecimento de espécies frutíferas, bem como na qualidade dos frutos e na produtividade, aumentando consideravelmen te os custos despendidos na cultura (DIASARIEIRA et al., 2010; FERRAZ et al., 2010). Ademais, o manejo inadequado da cultura ou a falta de conhecimento do agricultor podem contribuir para a disseminação dos nematoides, visto que estes patógenos são transportados via sementes, mudas, solo aderente aos veículos, máquinas e implementos agrícolas (VAN LEEUWEN \& SANTOS, 2001).

O conhecimento da nematofauna associada às fruteiras no Brasil ainda é escasso, principalmente no que tange a estudos realizados na região Norte do país. Neste sentido, devido à carência de estudos 
nematológicos no estado do Rondônia, este trabalho objetivou prospectar nematoides associados à rizosfera de espécies frutíferas, no distrito de Nova Califórnia, RO.

\section{MATERIAL E MÉTODOS}

Em janeiro de 2011 foram realizadas coletas de solo em quatro propriedades rurais, localizadas no distrito de Nova Califórnia, RO. As espécies frutíferas amostradas foram: abacaxi (0948'07.5's; 66³6'12.9”'W), açaí-de-touceira (0949'48.3”S; 66³5'54.4”W), acerola (0946'53.1'S; 6637'09.3'W), pupunha e cupuaçu (0945'42.9’'S; 66³6'19.2”W). Das plantas amostradas, apenas o açaí-detouceira é de ocorrência nativa, as demais foram plantadas em sistema de monocultivo, com exceção da aceroleira, a qual havia poucas plantas esparsas na propriedade.

Não foi possível obter informações sobre a idade das plantas, embora tenha sido verificado que todas já haviam atingido o estádio adulto e o abacaxizeiro se encontrava com frutos desenvolvidos, no momento da realização do levantamento. As frutíferas amostradas foram escolhidas pela carência de informações a respeito da nematofauna associada, pela importância que representam no comércio local e pela facilidade na realização das coletas. Em todas as áreas amostradas havia presença de vegetação rasteira, composta predominantemente por gramíneas no entorno das plantas, com exceção do plantio de abacaxi, o qual estava roçado no momento da realização do levantamento.

Foi amostrada a rizosfera de três plantas de cada fruteira, obedecendo a um distanciamento mínimo de cinco metros entre cada planta, totalizando 15 amostras ao todo. As amostras de solo (aproximadamente $500 \mathrm{~g}$ ) e raízes (aproximadamente $100 \mathrm{~g}$ ) foram retiradas, com auxílio de um enxadão, em três pontos da base das plantas, numa profundidade de aproximadamente $30 \mathrm{~cm}$, para compor amostras representativas da rizosfera de cada espécie botânica, seguindo recomendação de Goulart (2009) e de acordo com a utilizada por Dias-Arieira et al. (2010). O material foi acondicionado em sacos de polietileno, devidamente identificados e armazenados em caixas térmicas, sendo encaminhadas para $\mathrm{O}$ Laboratório de Nematologia da Faculdade de Ciências Agrárias e Veterinárias (FCAV/UNESP) em Jaboticabal, SP, onde foram armazenadas em câmara fria a $5^{\circ} \mathrm{C}$, por cerca de 24 horas, até o momento da extração.

A extração dos nematoides das amostras de solo foi realizada em alíquotas 
de $100 \mathrm{~cm}^{3}$, pelo método da flotação centrífuga, em solução de sacarose (JENKINS, 1964), e a extração de nematoides das raízes (alíquota de $10 \mathrm{~g}$ ), pelo método proposto por COOLEN \& D’HERDE (1972). Antes das extrações, as raízes foram lavadas, dissecadas sob microscópio estereoscópico e investigadas quanto à presença de fêmeas adultas, pertencentes ao gênero Meloidogyne Göldi, mesmo não apresentando galhas, segundo metodologia utilizada por Souza et al. (1999).

Os nematoides foram quantificados com auxílio de câmara de Peters, utilizandose microscópio fotônico, empregando-se a técnica de contagem proposta por Southey (1986). A identificação das espécies foi realizada com base nas características morfológicas e morfométricas do corpo dos espécimes, com utilização da chave dicotômica de Mai \& Mullin (1996) e com posterior confirmação pelo taxonomista Dr. Jaime Maia dos Santos (FCAV/UNESP, Jaboticabal, SP).

\section{RESULTADOS E DISCUSSÃO}

Foram encontradas oito espécies de nematoides associados à rizosfera das espécies frutíferas amostradas, pertencentes a seis gêneros distintos: Paratylenchus
Micoletzky, Tylenchus (Bastian), Pratylenchus Filipjev, Aphelencoides Fisher, Helicotylenchus Steiner, Rotylenchulus Linford e Oliveira e Mesocriconema Andrássy (Tabela 1).

Foi recuperado um total de 1.074 nematoides em todas as amostras processadas (Tabela 1 ), sendo $85,1 \%$ no solo e $14,9 \%$ nas raízes. A espécie com maior número de indivíduos, encontrados em 100 $\mathrm{cm}^{3}$ de solo, foi Tylenchus sp., considerando uma única planta hospedeira (E. oleraceae), bem como no cômputo geral (Tabela 1). Espécies deste gênero são comumente encontrados em muitos tipos de solo se alimentando de algas, musgos, liquens e raízes de plantas. São raros os relatos de espécies causando impactos econômicos (NEMAPLEX, 2015).

Em levantamento realizado em áreas produtoras de abacaxi, em Ji-Paraná, RO, Maciel et al. (2012) relataram cinco gêneros de nematoides associados ao abacaxizeiro, incluindo Pratylenchus, Helicotylenchus e Mesocriconema. Avaliando a incidência de nematoides em raízes de abacaxizeiro no estado do Acre, Cavalcante et al. (1984) observaram a presença de espécies dos gêneros Pratylenchus e Helicotylenchus na maioria das amostras. Zem \& Reinhardt (1978) constataram as espécies 
Helicotylenchus dihystera (Coob), Pratylenchus brachyurus (Godfrey) e Criconemoides Tylor, na rizosfera de abacaxizeiros no estado da Bahia. Vale salientar que a taxonomia dos gêneros Criconemoides e Criconemella é controversa e muitos autores os consideram sinonímia de Mesocriconema (NEMAPLEX, 2015).

Os resultados obtidos neste levantamento confirmam espécies de fitonematoides comumente relatadas associadas ao abacaxizeiro e aumentam o conhecimento de sua distribuição no estado de Rondônia. Sugere-se que os produtores de abacaxizeiro de Nova Califórnia façam análise nematológica do solo onde se pretende instalar o cultivo, ou mesmo em cultivos já instalados, visto que foi confirmada a presença de $P$. brachyurus na região, espécie de maior disseminação e poder patogênico na cultura do abacaxi (REINHARDT et al., 2000).

A aceroleira teve o maior número de nematoides associados à sua rizosfera neste levantamento (Tabela 1). Embora nematoides formadores de galhas (Meloidogyne spp.) sejam os principais fitonematoides, causadores de danos à cultura da aceroleira no Brasil (SOUZA et al., 1999; MOURA, 2005; DIAS-ARIEIRA et al., 2008), espécimes deste gênero não foram encontrados na rizosfera das aceroleiras amostradas neste levantamento. Além de um complexo de espécies de nematoides formadores de galhas, as espécies Helicotylenchus sp., Rotylenchulus reniformis Linford e Oliveira, Criconemella sp., Aphelencoides sp., Hemicycliophora sp. e Trichodorus sp., já foram relatadas associadas à rizosfera da aceroleira em vários Estados do Brasil (CAVALCANTE et al., 1980; MOURA et al., 2004; SAMPAIO et al., 2006; FERREIRA et al., 2007; LUQUINE et al., 2010).

Neste levantamento, adiciona-se Tylenchus sp. e Mesocriconema sp. à lista de nematoides associados à rizosfera da aceroleira no Brasil (Tabela 1).

Entretanto, testes de patogenicidade devem ser realizados, a fim de confirmar a aceroleira como hospedeira das espécies de nematoides encontradas em suas raízes, principalmente as espécies consideradas fitoparasitas (p. ex. R. reniformis).

Nas plantas de cupuaçu foram encontradas as espécies Tylenchus sp., Mesocriconema sp. e Pratylenchus zeae Graham. 
Tabela 1. Espécies e número total de nematoides, encontrados na rizosfera de cinco fruteiras no distrito de Nova Califórnia, RO, em janeiro de 2011.

\begin{tabular}{|c|c|c|c|c|c|c|c|c|c|c|}
\hline \multirow[t]{2}{*}{ Espécie de Nematoide } & \multicolumn{2}{|c|}{ Abacaxi } & \multicolumn{2}{|c|}{ Acerola } & \multicolumn{2}{|c|}{$\begin{array}{l}\text { Açaí-de- } \\
\text { touceira }\end{array}$} & \multicolumn{2}{|c|}{ Cupuaçu } & \multicolumn{2}{|c|}{ Pupunha } \\
\hline & Solo & Raiz & Solo & Raiz & Solo & Raiz & Solo & Raiz & Solo & Raiz \\
\hline $\begin{array}{l}\text { Rotylenchulus } \\
\text { reniformis }\end{array}$ & - & - & - & 4 & - & - & - & - & - & - \\
\hline $\begin{array}{l}\text { Pratylenchus } \\
\text { brachyurus }\end{array}$ & 4 & 36 & 8 & 8 & - & - & - & - & - & - \\
\hline Pratylenchus zeae & - & - & - & - & - & - & 36 & 20 & - & - \\
\hline $\begin{array}{l}\text { Helicotylenchus } \\
\text { dihystera }\end{array}$ & 132 & 28 & 4 & - & - & - & - & - & 12 & 4 \\
\hline Tylenchus sp. & - & - & - & 12 & 308 & 24 & 12 & - & 32 & - \\
\hline Aphelencoides sp. & - & - & - & - & - & 4 & - & - & - & - \\
\hline Paratylenchus sp. & - & - & - & - & 16 & 4 & - & - & 8 & - \\
\hline Mesocriconema sp. & 140 & 4 & 12 & 4 & - & - & 180 & 4 & - & - \\
\hline
\end{tabular}

No estado de Minas Gerais, Oliveira Júnior et al. (2013), estudando a associação de nematoides na cultura da bananeira, em consórcio com mangostão e cupuaçu, constataram Helicotylenchus sp. no solo e raízes e $R$. reniformis, somente no solo, em amostras coletadas em plantas de cupuaçu. No caso de $P$. zeae, esta espécie é cosmopolita e relatada como parasita de uma ampla gama de espécies cultivadas, destacando-se culturas de relevada importância econômica para o Brasil, tais como: soja, arroz, milho e cana-de-açúcar (AUNG \& PROT, 1990; MOURA \& OLIVEIRA, 2009; NEMAPLEX; 2015). Foi verificada a presença de $P$. zeae no solo e raízes de plantas de cupuaçu, o que pode indicar que esta planta também seja hospedeira desta espécie, embora haja a necessidade da realização de teste de patogenicidade. Entretanto, este é o primeiro relato desta espécie, encontrada na rizosfera de cupuaçuzeiro no Brasil.

Em pupunha, foram identificadas as espécies de $H$. dihystera, Tylenchus sp. e Paratylenchus sp. (Tabela 1). Helicotylenchus dihystera é considerada uma espécie ectoparasita e, em alguns casos semi-endoparasita, enquanto que o gênero Paratylenchus abriga espécies ectoparasitas (NEMAPLEX, 2015), desta forma sua associação com a pupunheira não pode ser descartada. No Brasil, não há registros de nematoides causando danos em pupunha, no entanto, ARROYO et al. (2004), em estudo de nematoides associados à pupunheira na Costa Rica, relataram Tylenchus sp., Ditylenchus sp., Pratylenchus sp., 
Criconemella spp., Boleodurus sp. e Meloidogyne sp. e Helicotylenchus sp., sendo esta última a mais comum e abundante. Segundo Krzyzanowski et al. (2000), em virtude de as raízes de $B$. gasipaes produzirem exsudados não atrativos aos nematoides, esta característica não a torna uma boa planta hospedeira para os mesmos.

Com relação ao açaí-de-touceira, por se tratar de uma planta explorada predominantemente de forma extrativista na Amazônia brasileira, de maneira geral há falta de informações fitossanitárias a respeito de seu cultivo. Neste estudo, espécimes do gênero Tylenchus foram os mais abundantes, encontrados na rizosfera de E. oleracea, predominantemente no solo mas, também nas raízes (Tabela 1). Embora tenha sido encontrada em grande quantidade em açaizeiro, a importância econômica do gênero Tylenchus é muito pequena, com raros relatos de espécies causadoras de injúrias em plantas cultivadas (NEMAPLEX, 2015).

Pelos resultados obtidos neste levantamento, foi verificada a presença de espécies de fitonematoides potencialmente danosas às plantas cultivadas, em Nova Califórnia. É costume dos produtores rurais da região Norte do Brasil, cultivarem frutíferas em Sistemas Agroflorestais (SAFs) (VIEIRA et al., 2007), com utilização de mudas, muitas vezes sem certificação fitossanitária. Neste contexto, como uma grande parte dos fitonematoides é polífaga (FERRAZ et al., 2010), as chances de disseminação destes patógenos no SAF ou pelo comércio informal de mudas é muito grande. Assim, sugere-se que análises nematológicas sejam realizadas, anteriormente ao plantio de frutíferas na região, a fim de verificar a presença de fitonematoides na área e para que medidas que visem seu controle e mitigação sejam adotadas.

\section{CONCLUSÕES}

O maior número de espécies de nematoides foi registrado associado à rizosfera da aceroleira (Malpighia sp.)

São primeiros registros de nematoides em rizosferas de cupuaçu (Pratylenchus zeae), acerola (Tylenchus sp. e Mesocrinocema sp.), pupunha (Helicotylenchus dihystera, Tylenchus sp. e Paratylenchus sp.) e açaí (Tylenchus sp., Paratylenchus sp. e Aphelencoides sp.) no Brasil. 


\section{AGRADECIMENTOS}

À mestranda Luciana Maira de Sales Pereira (Instituto Federal do Acre - IFAC) pela revisão do texto e Abstract. Ao técnico do laboratório de Nematologia, André Maurício Múscari e ao Dr. Jaime Maia dos Santos (Faculdade de Ciências Agrárias e Veterinárias - FCAV/UNESP), pelo auxílio na preparação das amostras e na identificação dos nematoides.

\section{REFERÊNCIAS}

ARROYO, C.; MORA, J.; SALAZAR, L.; QUESADA, M. 2004. Dinámica poblacional de nemátodos fitoparásitos en pejibaye (Bactris gasipaes K.) para palmito. Agronomia Mesoamericana, Alajuela, v.15, n.1, p.53-59.

AUNG, T.; PROT, J.C. 1990. Effects of crop rotation on Pratylenchus zeae and on yield of cultivar UPLRi-5. Revue de Nématologie, Paris, v.13, n.4, p.445-447.

CAMPOS, V.P.; CAMPOS, J.R.; SILVA, L.H.C.P.; DUTRA, M. R. 2002. Manejo de doenças causadas por nematoides em frutíferas. In: ZAMBOLIM, L. (Ed.). Manejo integrado: fruteiras tropicais, doenças e pragas. Viçosa: Suprema Gráfica e Editora. 587p.

CAVALCANTE, U.M.T., MOURA, R.M., CAVALCANTE, A.T.; MOURA, R.J.M. 1980. Nematóides fitoparasitos associados a raízes de bananeiras no Estado de Pernambuco. In: XIII CONGRESSO BRASILEIRO DE FITOPATOLOGIA, Rio de Janeiro, RJ. Resumos... Rio de Janeiro. p.77.

CAVALCANTE, U.M.T.; WARUMBI, J.F.; BEZERRA, J.E.F.; MOURA R.M. de. 1984.
Nematoides associados ao abacaxizeiro no estado de Pernambuco. In: REUNIÃO BRASILEIRA DE NEMATOLOGIA, 8. Recife, PE. Anais... Sociedade Brasileira de Nematologia. p.24.

COOLEN, W.A.; D'HERDE, C.J.D. 1972. A method for the quantitative extraction of nematodes from plant tissue culture. Ghent, Belgian: State Agriculture Research Centre. $77 \mathrm{p}$.

DIAS-ARIEIRA, C.R.; FURLANETTO, C.; SANTANA, S. de M.; BARIZÃO, D.A.O.; RIBEIRO, R.C.F.; FORMENTINI, H.M. 2010. Fitonematoides associados a frutíferas na região Noroeste do Paraná, Brasil. Revista Brasileira de Fruticultura, Jaboticabal, v.32, n.4, p.1064-1071.

DIAS-ARIEIRA, C.R.; MOLINA, R. de O.; COSTA, A.T. 2008. Nematóides causadores de doenças em frutíferas. Agro@mbiente On-line, Boa Vista, v.2, n.1, p.46-56.

FERRAZ, S.; FREITAS, L. G. de; LOPES, E.A.; DIAS-ARIEIRA, C.R. 2010. Manejo sustentável de fitonematoides. Viçosa: Editora UFV. 304p.

FERREIRA， R.V.; OTOBONI， C.E.M.; CRUZ, M.C.; GOULART, S.L. 2007. Ocorrência de nematóides nas culturas da aceroleira, goiabeira e pessegueiro. Revista Científica Eletrônica de Agronomia, Garça, v.7, n.12, p.1-7.

FUNDAÇÃO BANCO DO BRASIL. 2010. Fruticultura - Açaí. Desenvolvimento Regional Sustentável. Brasília: Fundação Banco do Brasil. 52p. (Série cadernos de propostas para atuação em cadeias produtivas, 2). Disponível em: $<$ http://www.bb.com.br/docs/pub/inst/dwn/V ol2FruticAcai.pdf $>$. Acesso em: 07 de Abr. de 2016.

GOUlART, A.M.C. 2009. Coleta de amostras para análise de nematoides: recomendações gerais. Planaltina, DF: 
Embrapa Cerrados. 31p. (Embrapa Cerrados, Documento, 255).

JENKINS, W.R. 1964. A rapid centrifugalflotation technique for separating nematodes from soil. Plant Disease Reporter, Washington, v.48, n.4, p.692.

KRZYZANOWSKI, A.A.; SANTIAGO, D.C.; GIROTTO, H.X. 2000. Hospedabilidade da pupunha (Bactris gasipaes) frente às raças de Meloidogyne incognita, M. paranaensis e $M$. javanica. In: XXIII CONGRESSO BRASILEIRO DE NEMATOLOGIA. Uberlândia, MG. Anais... Uberlândia: Sociedade Brasileira de Nematologia. p.120-121.

LUQUINE, L.S.; RITZINGER, R.; RITZINGER, C.H.S.P.; VIEIRA, R.S.; SANTOS, J.F. dos; CRUZ, E.S. da. 2010. Comportamento da população de nematóides em aceroleira cultivada no sistema orgânico. In: XXI CONGRESSO BRASILEIRO DE FRUTICULTURA. Natal, RN. Anais... Natal: Sociedade Brasileira de Fruticultura. $4 \mathrm{p}$.

MACIEL, L.O.; RAMALHO, P. dos A.; LEONEL, D.C.; SANTOS, A.V. 2012. Nematoides associados à cultura do abacaxi (Ananas comosus (L.) Merril) em áreas produtoras de Ji-Paraná, RO. In: XIV SALÃO DE INICIAÇÃO CIENTÍFICA CEULJI/ULBRA, 2012, Ji-Paraná.

MAI, W.F.; MUlliN, P.G. 1996. Plant parasitic nematodes: a pictorial key to genera. $5^{\text {th }}$ ed., Ithaca: Cornell University Press. 288p.

MARQUES, E. 2012. Produtores rurais estão otimistas com produção de $2012 \mathrm{em}$ Ariquemes, RO. Disponível em: $<$ http://g1.globo.com/ro/rondonia/noticia/20 $12 / 10$ /produtores-rurais-estao-otimistascom-producao-de-2012-em-ariquemesro.html> Acesso em: 07 de Abr. de 2015.

MOURA, R.M. 2005. Nematóides de interesse agrícola assinalados pelo laboratório de Nematologia da UFRPE, no Nordeste do Brasil (1967-2004). Anais da Academia Pernambucana de Ciência Agronômica, Recife, v.2, p.166-171.

MOURA, V. 2014. Confira a lista das dez frutas mais produzidas em Rondônia. Disponível em:

$<$ http://portalamazonia.com/noticiasdetalhe/cidades/confira-a-lista-das-dezfrutas-mais-produzidas-emrondonia/? $\mathrm{cHash}=\mathrm{c} 12 \mathrm{e} 0008653 \mathrm{a} 13 \mathrm{bd} 5 \mathrm{a} 72 \mathrm{e} 2$ 32d7de6abd> Acesso em: 07 de Abr. De 2016.

MOURA, R.M.; OLIVEIRA, I.S. 2009. Controle populacional de Pratylenchus zeae em cana-de-açúcar em dois ambientes edáficos no Nordeste do Brasil. Nematologia Brasileira, São Paulo, v.33, n.1, p.67-73.

NASCENTE, A.S.; ROSA NETO, C. 2005. $\mathrm{O}$ agronegócio da fruticultura na Amazônia. Porto Velho, RO: Embrapa Rondônia. 24p. (Embrapa Rondônia, Documentos, 96).

Nematode-Plant Expert Information System - NEMAPLEX DATABASE. 2015. Disponível em: $<$ http://plpnemweb.ucdavis.edu/nemaplex/> Acesso em: 07 de Abr. De 2016.

OLIVEIRA JÚNIOR, J.L.; JESUS, A.M. de; RODRIGUES, M.G.V.; SILVA, P.B.; DIAS, M.S.C. 2013. Levantamento populacional de nematoides no consórcio de banana 'PrataAnã' com fruteiras no Norte de Minas. In: X SEMINÁRIO DE INICIAÇÃO CIENTÍFICA E TECNOLÓGICA. Belo Horizonte, MG. Resumos... Belo Horizonte: EPAMIG. 5p.

REINHARDT, D.H.; SOUZA, L.F. da S.; CABRAL, J.R.S. Abacaxi - Produção. Cruz das Almas, BA: Embrapa Mandioca e Fruticultura. 77p. (Embrapa Mandioca e Fruticultura, Frutas do Brasil, 7).

ROSA NETO, C.; ALMEIDA, C.O. 2007. O sistema agroindustrial de frutas em 
Rondônia: um diagnóstico. In: XLV CONGRESSO BRASILEIRO DE ECONOMIA, ADMINISTRAÇÃO E SOCIOLOGIA RURAL. Londrina, PR. Anais... Londrina: SOBER. 19p.

SAMPAIO, A.H.R.; RITZINGER, R.; RITZINGER, C.H.S.P.; DAMASCENO, J.C.A.S.; SANTOS, V.S.; SEVERINO, L.S.; LEDO, C.A.S. 2006. Controle de fitonematóides em aceroleira mediante o uso de farelo de mamona. In: $2^{\circ}$ CONGRESSO BRASILEIRO DE MAMONA. Aracaju, SE. Resumos... Aracaju: Embrapa Tabuleiros Costeiros. 8p.

SOUTHEY, J.F. 1986. Laboratory methods for work with plant and soil nematodes. $6^{\text {th }}$ ed. London UK. Ministry of Agriculture Fisheries and Food. 202p.

SOUZA, J.T. de.; MAXIMINIANO, C.; CAMPOS, V. P. 1999. Nematóides associados a plantas frutíferas em alguns estados brasileiros. Ciência e Agrotecnologia, Lavras, v.23, n.2, p.353357.

TIMMER, L.W.; GARNSEY, S.M.; BROADBENT, P. 2003. Diseases of citrus. In: PLOETZ, R. C. (Ed.). Diseases of tropical fruit crops. London: $\mathrm{CAB}$ International, 2003. 512p.

VAN LEEUWEN, K.; SANTOS, J.M. dos. 2001. Flores do Mal. Revista Cultivar Hortaliças e Frutas, Pelotas, n.6, p.22-23.

VIEIRA, T.A.; ROSA, L. dos S.; VASCONCELOS, P.C.S.; SANTOS, M.M. dos; MODESTO, R. da S. 2007. Sistemas agroflorestais em áreas de agricultores familiares em Igarapé-Açu, Pará: caracterização florística, implantação e manejo. Acta Amazonica, Manaus, v.37, n.4, p.549-558.

ZEM, A.C.; REINHARDT, D.H. 1978. Nematóides associados à cultura do abacaxi no estado da Bahia. Sociedade Brasileira de Nematologia, São Paulo, v.3, p.17-20. 